\title{
Benzimidazole, coumrindione and flavone derivatives as alternate UV laser desorption ionization (LDI) matrices for peptides analysis
}

Syed Ghulam Musharraf ${ }^{1,2 *}$, Aisha Bibi ${ }^{2}$, Najia Shahid ${ }^{2}$, Muhammad Najam-ul-Haq ${ }^{3}$, Nida Ambreen ${ }^{2}$, Momin Khan², Khalid Mohammed Khan', M lqbal Choudhary ${ }^{1,2}$ and Atta ur Rahman ${ }^{1,2}$

\begin{abstract}
Background: Matrix-assisted laser desorption/ionization (MALDI) is a soft ionization mass spectrometric technique, allowing the analysis of bio-molecules and other macromolecules. The matrix molecules require certain characteristic features to serve in the laser desorption/ionization mechanism. Therefore, only a limited number of compounds have been identified as ultraviolet- laser desorption/ionization (UV-LDI) matrices. However, many of these routine matrices generate background signals that useful information is often lost in them. We have reported flavones, coumarindione and benzimidazole derivatives as alternate UV-LDI matrices.

Results: Thirty one compounds have been successfully employed by us as matrices for the analysis of low molecular weight (LMW) peptides (up to 2000 Da). Two peptides, bradykinin and renin substrate tetra-decapeptide were analyzed by using the newly developed matrices. The MS measurements were made after mixing the matrix solution with analyte by using dried droplet sample preparation procedures. The synthesized matrix materials showed better $\mathrm{S} / \mathrm{N}$ ratios and minimal background signals for low mass range. Furthermore, pico molar concentrations of $\left[\mathrm{Glu}^{1}\right]$-fibrinopeptide B human could be easily analyzed with these matrices. Finally, BSA-digest was analyzed and identified through database search against Swiss-Prot by using Mascot.
\end{abstract}

Conclusions: These results validate the good performance of the synthesized UV-laser desorption/ionization (LDI) matrices for the analysis of low molecular weight peptides.

Keywords: MALDI-MS, LDI matrix, Benzimidazole derivatives, Coumarin derivatives, Flavones, Peptides

\section{Introduction}

MALDI-MS was developed in the late 1980s and since then it has become a powerful tool for the analysis of large biomolecules, such as proteins, peptides, and nucleic acids, etc. [1]. Two important factors that involved in the ionization of analytes in the MALDI processing are laser and matrices. MALDI techniques commonly employ the use of UV lasers such as nitrogen lasers $(337 \mathrm{~nm})$ and frequency-tripled and quadrupled $\mathrm{Nd}$ : YAG lasers (355 nm and $266 \mathrm{~nm}$, respectively) as a

\footnotetext{
* Correspondence: musharraf1977@yahoo.com

${ }^{1}$ Dr. Panjwani Center for Molecular Medicine and Drug Research, International Center for Chemical and Biological Sciences, University of Karachi, Karachi 75270, Pakistan

${ }^{2}$ H.E.J. Research Institute of Chemistry, International Center for Chemical and Biological Sciences, University of Karachi, Karachi 75270, Pakistan

Full list of author information is available at the end of the article
}

energy source. Moreover, radiation from IR laser such as Er: YAG lasers and $\mathrm{CO}_{2}$ are also employed [2]. Several modifications have been made on UV lasers to improve the performance. Recently, a modified laser named "smartbeam" has been introduced by the Bruker which is a combination of the speed of a solid-state-laser and the wide range of nitrogen lasers and provides substantial improvement in MALDI performance [3].

MALDI matrices are generally small organic compounds and act as energy mediators, effectively transferring the laser energy from a source to the surrounding sample molecules, resulting in minimum fragmentation. The method involves both laser ablation and ionization of the matrix/analyte mixture after electronic excitation of the matrix [4]. It is generally observed that effective LDI matrices have an aromatic conjugated system in
() Chemistry Central

(c) 2013 Musharraf et al.; licensee Chemistry Central Ltd. This is an Open Access article distributed under the terms of the Creative Commons Attribution License (http://creativecommons.org/licenses/by/2.0), which permits unrestricted use, distribution, and reproduction in any medium, provided the original work is properly cited. 
Table 1 The $\lambda_{\max }$ and molar absorptivities of different classes of compounds

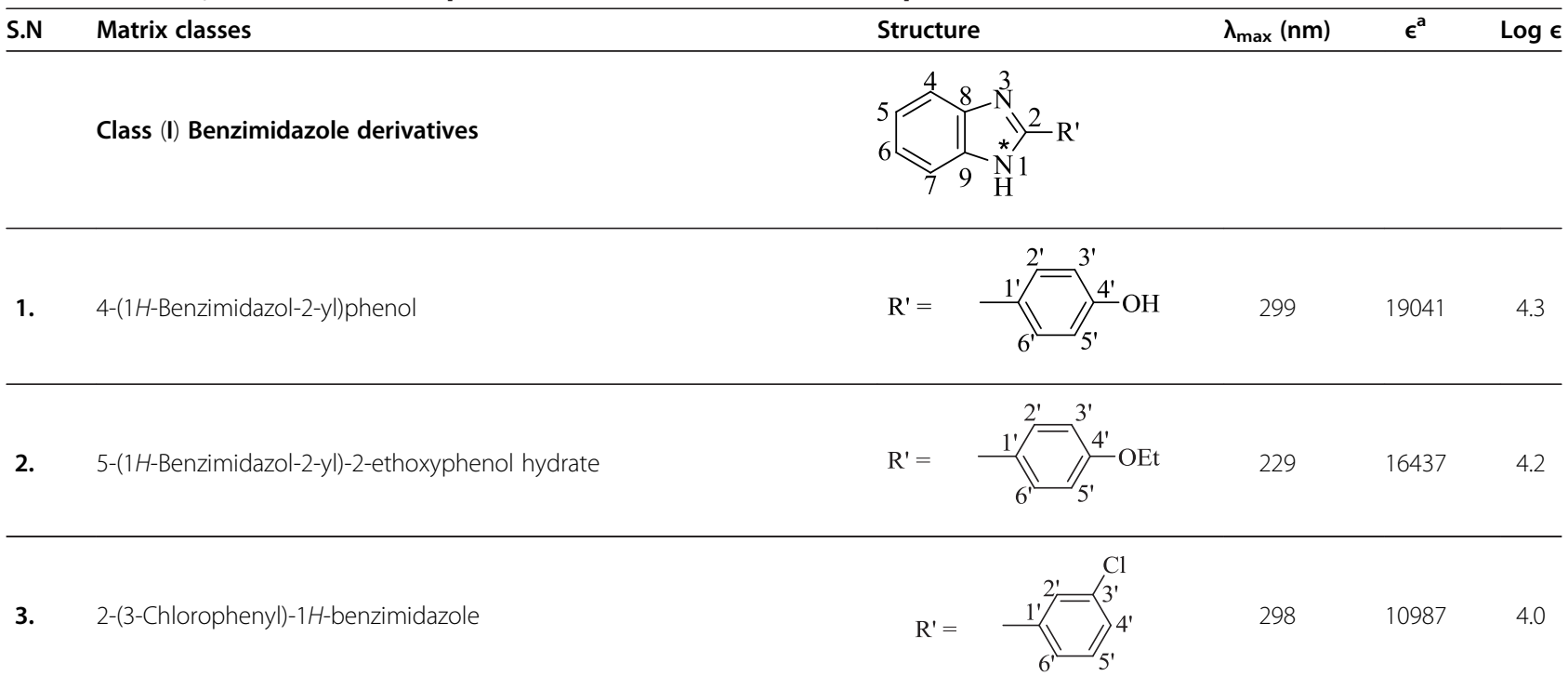

4. 2-(1-Naphthyl)-1H-benzimidazole

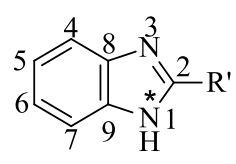

5. 2-(3,4-Dimethoxyphenyl)-1-phenyl-1H- benzimidazole

$\mathrm{R}^{\prime}=$

6. 2-(1H-Benzimidazol-2-yl)-5-hydroperoxyphenol<smiles>[R]#Cc1ccc(C(C)C)cc1</smiles>

7. 2-(4-Isopropylphenyl)-1H-benzimidazole

$$
\mathrm{R}^{\prime}=
$$

8. $\quad 3-(1 H-B e n z i m i d a z o l-2-y l)$ phenol<smiles>[R]=C1CC(Cl)=[C+]C=C1O</smiles>

9. 2-(1H-Benzimidazol-2-yl)-4-chlorophenol 
Table 1 The $\lambda_{\max }$ and molar absorptivities of different classes of compounds (Continued)

11. N, N-Dimethyl-4-(1-phenyl-1H-benzimidazol-2-yl) aniline

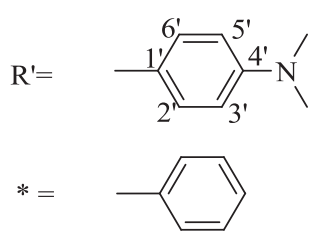

12. 2-(3,4-Dimethoxyphenyl)-1H-benzimidazole<smiles>[R]c1ccc(OC)c(OC)c1</smiles>

13. 2-(3,4-Dichlorophenyl)-1H-benzimidazole<smiles>[R]c1ccc(Cl)c(Cl)c1</smiles>

14. 2-(1H-Benzimidazol-2-yl)-1,4-benzenediol<smiles>[R]Cc1cc(O)[c-][14cH][14c]1O</smiles>

\section{Class-11 (Coumarin derivative)}<smiles>[R]C=C1C(=O)Oc2ccccc2C1=O</smiles>

15. 3-[(5-Methyl-2-furyl)methylidene]-2H-chromene-2,4-dione

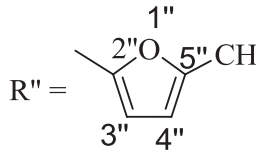

16. 3-[(2-Bromophenyl)methyl idene]-2H-chromene-2,4-dione

$$
\mathrm{R}^{\prime \prime}=\overbrace{6^{\prime \prime}}^{\mathrm{Br}}>^{\prime \prime}
$$

17. 3-[(2-Nitrophenyl)methyl idene]-2H-chromene-2,4-dione

$$
\mathrm{R}^{\prime \prime}=\mathrm{6}_{6^{\prime \prime}}^{\mathrm{O}_{2} \mathrm{~N}}>_{4 "}^{211}
$$

18. 3-[(2,4-Dihydroxy phenyl)methylidene]-2H-chromene-2,4-dione

$$
\mathrm{R}^{\prime \prime}=\left.\underbrace{2 " \mathrm{O} / 4_{4}^{\prime \prime}}_{3 "}\right|^{\prime \prime}
$$

19. 3-[2-Furylmethylidene]-2H-chromene-2,4-dione 
Table 1 The $\lambda_{\max }$ and molar absorptivities of different classes of compounds (Continued)

20. 3-[(2,3,4-Trihydroxyphenyl) methyl idene]-2H-chromene-2,4-dione

$$
\mathrm{R}^{\prime \prime}=\underbrace{\text { 5" }}_{6^{\prime \prime}}
$$

21. 3-[(2-Ethoxyphenyl)methyl idene]-2H-chromene-2,4-dione

$$
\mathrm{R}^{\prime \prime}=\overbrace{6^{\prime \prime}}^{\mathrm{EtO}} 4
$$

22. 3-[(2-Hydroxy-3-methoxy phenyl)methylidene]-2H-chromene-2,4-dione

$$
\mathrm{R}^{\prime \prime}=\underbrace{\mathrm{HO}}_{6^{\prime \prime}}>_{5^{\prime \prime}}^{2 "} \mathrm{OCH}_{3 "}
$$

23. 3-[(2-Fluorophenyl) methylidene]-2H-chromene-2,4-dione

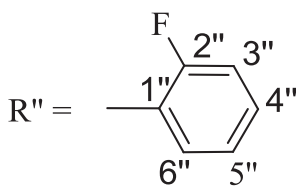

24. 3-[(3-Fluorophenyl) methylidene]-2H-chromene-2,4-dione

$$
\mathrm{R}^{\prime \prime}=\underbrace{2 "}_{6^{\prime \prime}}>_{5 "}^{\mathrm{F}} \mathrm{S}^{\prime \prime}
$$

25. 3-[(4-Hydroxyphenyl)methyl idene]-2H-chromene-2,4-dione

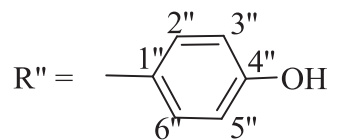

26. 4-Methyl-2H-chromen-2-one<smiles>Cc1cc(=O)oc2ccccc12</smiles>

Class-III (Flavones)<smiles>[R]c1cc([R3])c2c(=O)cc([R])oc2c1</smiles>

27. 7-Hydroxy-2-phenyl-4H-chromen-4-one<smiles>[R]c1ccccc1</smiles>

$$
\begin{aligned}
& \mathrm{R}_{2}=\mathrm{H} \\
& \mathrm{R}_{3}=\mathrm{OH}
\end{aligned}
$$


Table 1 The $\lambda_{\max }$ and molar absorptivities of different classes of compounds (Continued)

28. 5-Methyl-2-phenyl-4H-chromen-4-one

$\mathrm{R}_{1}=\underbrace{}_{\mathrm{R}_{2}}=\mathrm{H}$
$\mathrm{R}_{3}=\mathrm{CH}_{3}$

29. 5,7-Dihydroxy-2-phenyl-4H-chromen-4-one<smiles>[R]c1ccccc1</smiles>

$$
\begin{aligned}
& \mathrm{R}_{2}=\mathrm{OH} \\
& \mathrm{R}_{3}=\mathrm{OH}
\end{aligned}
$$

30. 2-(3,4-Dimethoxyphenyl)-4H-chromen-4-one

$\mathrm{R}_{1}=$
$\mathrm{R}_{2}=\mathrm{H}$
$\mathrm{R}_{3}=\mathrm{H}$

31. 2-(3,4-Dimethoxyphenyl)-7-methyl-4H-chromen-4-one

$\begin{array}{ll}\mathrm{R}_{1}= & \\ \mathrm{R}_{2}=\mathrm{CH}_{3} \\ \mathrm{R}_{3}=\mathrm{H}\end{array}$

their structures which enhance the energy absorbing capacity from UV laser. This phenomenon is still relatively unclear therefore certain molecule can act as matrices and others not [5]. Moreover, routinely used commercially available matrices such as HCCA ( $\alpha$-cyano-4hydroxycinnamic acid), DHB (2,5-dihydroxybenzoic acid) and SA (sinapinic acid) also get ionized, producing large number of background signals in the low-mass region which restricted the use of MALDI for the determination of low molecular weight analyte. In the investigations of low molecular weight compounds, a number of new matrices and many modifications of the MALDI targets have been accomplished [6-25].

In an attempt to correlate the performance of a matrix in a MALDI experiment with its chemical structure, we studied thirty one synthetic alternate matrices for their desorption and ionization of intact small peptides. A large number of derivatives of flavones, coumarindione (coumarin derivative) and benzimidazol with necessary functionalities have been screened as potential matrices without any tedious chemical modification or applying expensive procedures.

\section{Experimental}

\section{Chemicals and reagents}

HPLC grade methanol, trifluoro acetic acid, acetone, and acetonitrile were purchased from Sigma-Aldrich (USA). All standards, ([Glu $\left.{ }^{1}\right]$-fibrinopeptide B human (Glufib, $\geq 90 \%$ ), bradykinin ( $\geq 97 \%$ ) and renin substrate tetra-decapeptide $(\geq 97 \%)$, were obtained from SigmaAldrich (USA). Cholic acid $(\geq 97 \%)$ was obtained from Wako (Japan) while bovine serum albumin (BSA)-digest was purchased from Bruker Daltonics (Germany). Deionized water (Milli-Q) was used throughout the study (Millipore, USA). 2-Phenylenediamine, 4-hydroxy coumarin, ethyl benzoyl acetate, phloroglucinol and the other reagents and solvents used in the preparation of matrices were of synthetic grades, obtained from SigmaAldrich (USA).

\section{Preparation of matrix materials}

Benzimidazole derivatives were synthesized by reacting together commercially available 2-phenylenediamine and different substituted aromatic aldehydes in $\mathrm{N}, \mathrm{N}$ dimethylformamide (DMF). The mixture was heated to 
reflux for $2 \mathrm{~h}$; the progress of the reaction was monitored by TLC. After completion of the reaction, the mixture was allowed to cool to room temperature. Addition of water resulted in precipitation of a solid material, after filtration, the solid benzimidazole derivatives were obtained in high yields [26]. Coumarindione (coumarin derivative) were synthesized by taking a mixture of different substituted benzaldehyde and 4-hydroxy coumarin in water. Heating and stirring was continued for $1-2 \mathrm{~h}$ at $100^{\circ} \mathrm{C}$. The reaction progress was monitored by TLC. On completion, the solid was filtered and washed subsequently with boiling water and hexane. After drying in vacuum, the coumarindione was obtained as a solid product. Flavones were synthesized by mixing different substituted aromatic $\beta$-ketoesters and substituted phenols, followed by irradiation with microwaves $300 \mathrm{~W}$ at $100^{\circ} \mathrm{C}$ for $3 \mathrm{~min}$. The crude product was dissolved in $10 \%$ aq. $\mathrm{NaOH}$ and washed with diethyl ether. The product was precipitated by adding concentrated $\mathrm{HCl}$, which was filtered, washed with water and vacuum-dried to obtain the desired flavones [27].

\section{Preparation of standard solutions}

Peptide standards, bradykinin and renin substrate tetradecapeptide, were dissolved in 0.1\% TFA: ACN (1:1), while cholic acid was dissolved in methanol $(1 \mathrm{mg} / \mathrm{mL})$. The stock solution of peptide standards was prepared in a $1 \mathrm{mM}$ concentration, and working standard solutions of $25 \mathrm{pM}$ were prepared through the dilution of stock solution. BSA-digest was dissolved in $0.1 \%$ trifluoroacetic acid (TFA) in a concentration of $4 \mathrm{pM}$. [Glu ${ }^{1}$-fibrinopeptide B human was used for sensitivity measurements in different concentrations of 1000, 100, 50, 25, 12.5 and $10 \mathrm{pM}$.

\section{UV-Vis absorption measurements}

Synthesized materials of benzimidazole, flavones and coumarindione derivatives were dissolved in methanol having concentration of $1.0-0.5 \mathrm{mM}$. The absorption maxima was recorded by UV/Visible scanning in the region of 200-800 nm against the reagent blank on a UV/ Visible double beam spectrophotometer (Thermo Scientific Evolution 300, UK), $\epsilon$ and $\log \epsilon$ were calculated at $\lambda_{\max }$ by Lambert-Beer law.

\section{Instrumentation}

MALDI-MS measurements were carried out on Ultraflex III TOF/TOF (Bruker Daltonics, Bremen, Germany) mass spectrometer, equipped with a smartbeam laser (Nd: YAG, $355 \mathrm{~nm}$, maximum pulse energy of $300 \mu \mathrm{J}$, beam diameter $0.4 \mathrm{~mm}$ ) and an electrostatic reflector. The focal length of lense is $50 \mathrm{~mm}$. Mass spectra were recorded in reflector mode with the ion source 1 (ISI) set to $25.00 \mathrm{kV}$, source 2 (ISI) set to $21.50 \mathrm{kV}$, a lens voltage of $9.51 \mathrm{kV}$ and performed with the laser energies of $55 \pm 5 \%$. The validation of data including the baseline subtraction was obtained through Flex analysis. External calibration was carried by using peptide calibration standards (Bruker Daltonics, Bremen,Germany). 0.1\% TFA solution was prepared in deionized water and synthetic matrix materials were dissolved in different concentration (1-2 mM) in the solvent system of $0.1 \%$ TFA: ACN (1:1). The solution was sonicated for 5 minutes on a sonicator (Ultrasonic LC $38 \mathrm{H}$ ), followed by centrifugation (Centrifuge

Table 2 Signal intensity and $\mathrm{S} / \mathrm{N}$ ratio of synthetic matrix material with low molecular weight analytes

\begin{tabular}{|c|c|c|c|c|}
\hline \multirow[t]{2}{*}{ Compounds } & \multicolumn{2}{|c|}{ Bradykinin $^{a}$} & \multicolumn{2}{|c|}{ Renin substrate tetra-decapeptide $^{a}$} \\
\hline & $S / N$ & Sig. Int. & $\mathrm{S} / \mathrm{N}$ & Sig. Int. \\
\hline 1 & 711 & 56530 & 551 & 47162 \\
\hline 2 & 540 & 23276 & 423 & 23276 \\
\hline 3 & 547 & 61687 & 228 & 23778 \\
\hline 4 & 447 & 64184 & 205 & 50958 \\
\hline 5 & 965 & 179163 & 579 & 39417 \\
\hline 6 & 612 & 73058 & 450 & 40258 \\
\hline 7 & 403 & 98986 & 586 & 132521 \\
\hline 8 & 710 & 105850 & 689 & 68272 \\
\hline 9 & 148 & 254785 & 435 & 32688 \\
\hline 10 & 250 & 38696 & 411 & 59285 \\
\hline 11 & 568 & 129858 & 361 & 80878 \\
\hline 12 & 524 & 157277 & 360 & 144048 \\
\hline 13 & 548 & 58187 & 620 & 105141 \\
\hline 14 & 520 & 131703 & 668 & 127967 \\
\hline 15 & 612 & 17858 & 402 & 55811 \\
\hline 16 & 369 & 24724 & 463 & 65700 \\
\hline 17 & 250 & 57522 & 432 & 81912 \\
\hline 18 & 332 & 101983 & 299 & 61957 \\
\hline 19 & 294 & 55402 & 200 & 13615 \\
\hline 20 & 286 & 13022 & 514 & 14110 \\
\hline 21 & 244 & 53297 & 446 & 36294 \\
\hline 22 & 427 & 88683 & 642 & 101135 \\
\hline 23 & 455 & 85541 & 650 & 53205 \\
\hline 24 & 328 & 11451 & 519 & 81163 \\
\hline 25 & 850 & 16992 & 574 & 85517 \\
\hline 26 & 402 & 14593 & 436 & 79334 \\
\hline 27 & 370 & 26798 & 444 & 66542 \\
\hline 28 & 202 & 10398 & 221 & 13736 \\
\hline 29 & 727 & 115238 & 309 & 124664 \\
\hline 30 & 708 & 10452 & 125 & 16030 \\
\hline 31 & 806 & 89386 & 66 & 18759 \\
\hline HCCA & 832 & 86824 & 792 & 147702 \\
\hline
\end{tabular}




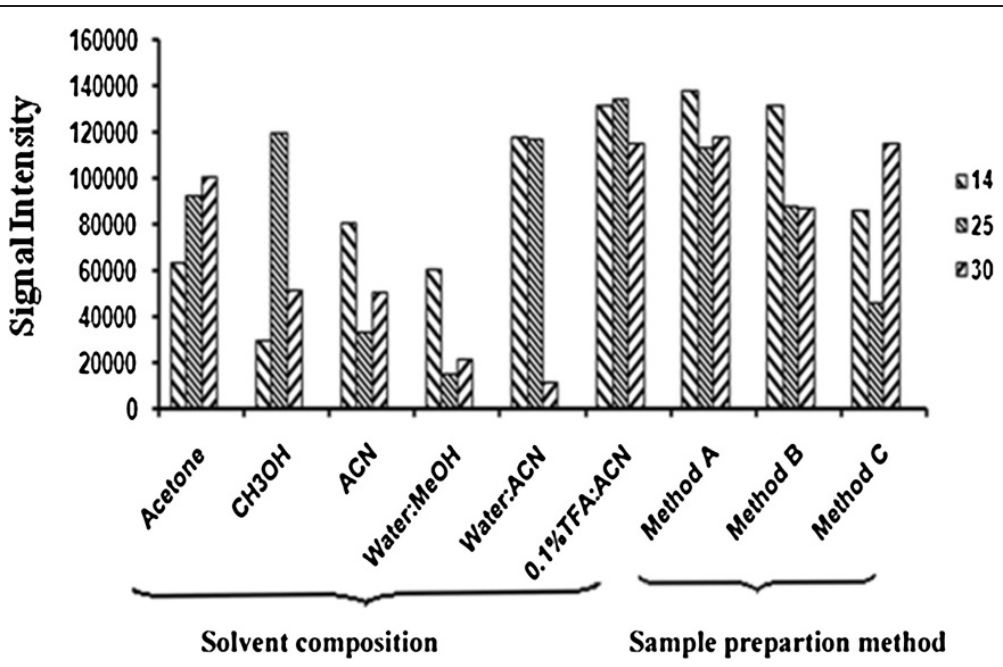

Figure 1 Solvent and method optimization of various matrices with bradykinin.

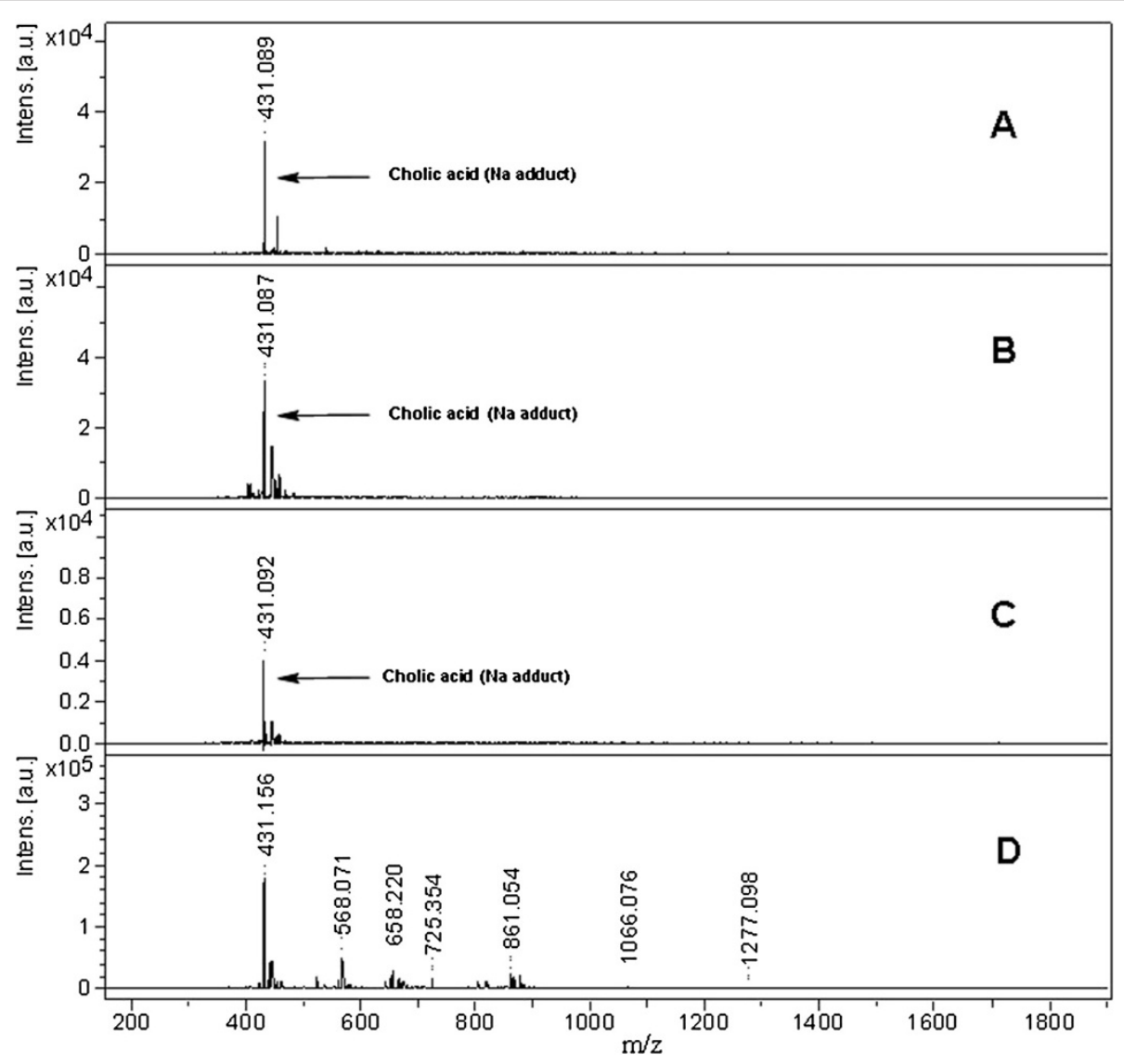

Figure 2 MALDI mass spectra of cholic acid $(\mathrm{M} . w \mathrm{wt}=408.58 \mathrm{Da}, 0.1 \mu \mathrm{M})$, recorded in reflector mode by averaging 600 laser shots with smart beam (355 nm) on MALDI-TOF-MS by applying different compounds as a matrix (A) 6 (B) 25 (C) 29 (D) HCCA. 
5804R Eppendorf). The supernatant was employed as a matrix. All measurements were made after mixing the matrix solution with analyte at a volume ratio of $1: 2$, spotted $1.5 \mu \mathrm{L}$ droplet of mixture on the MALDI target plate (MTP 384, spot diameter $3.5 \mathrm{~mm}$ ) and allowing the droplet to dry at ambient conditions. The dried droplet preparation method was used for the sample preparation. The dried co-crystallized sample was then analyzed by MALDI-MS. To improve the signal-to-noise ratio, spectral data from every 200 laser shots were summed. Then, the results from 3 different locations on a sample spot were summed. Hence, each point in such spectra corresponds to the summation of over 600 shots. The background spectra of matrices was recorded on off mode (provided in the Additional file 1: Figure S1) while with the analyte, the spectra were recorded on deflection mode in order to minimize all background signals generating from matrix.

Recorded BSA digest spectra with various matrices was submitted to the MASCOT search engine (Matrix Science, London, UK), using UniProt/Swiss-Prot (release July 2010, Homo sapiens, 18055 sequences) as the reference database. Mascot search parameters were as follows: enzyme specificity trypsin, fixed modifications cysteine carbamidomethylation, variable modification methionine oxidation. The maximum number of missed cleavages was set to 3 and mass tolerance at (0.1-0.9 Da). Stereomicroscopic image of matrices spots were recorded by using Nikon SMZ 800 (Japan) fitted with (DS-Vi1) camera.

\section{Results and discussion}

Synthesized matrix materials of different classes of compounds, including benzimidazole derivatives (class I, fourteen compounds), coumarindiones (class II, twelve coumarin derivatives) and flavones (class III, six compounds) were evaluated as alternate matrices for the detection of low molecular weight peptides (Table 1). Wavelength maxima $\left(\lambda_{\max }\right)$ of synthetic matrix materials were measured to verify their ability to absorb the laser energy at proper $\lambda_{\max }$ employed in ultraviolet-Matrix -assisted laser desorption/ionization mass spectrometry (UV-MALDI-MS). Spectrum quality generally increases with absorption [28], best mass spectrometric performances were observed at wavelengths near absorption maxima of matrices [4]. However, the desorption/ionization process is not solely dependent upon this relationship, as few good working routine matrices have $\lambda_{\max }$ quite far away from $\mathrm{N}_{2}$ laser, $(377 \mathrm{~nm})$, like nicotinic acid $(260 \mathrm{~nm})$, picolinic acid $(266 \mathrm{~nm})$, etc. [29]. Therefore, it is often believed that the matrices based desorption/ionization mechanism is still not completely understood. MALDI software generated signal intensities and $\mathrm{S} / \mathrm{N}$

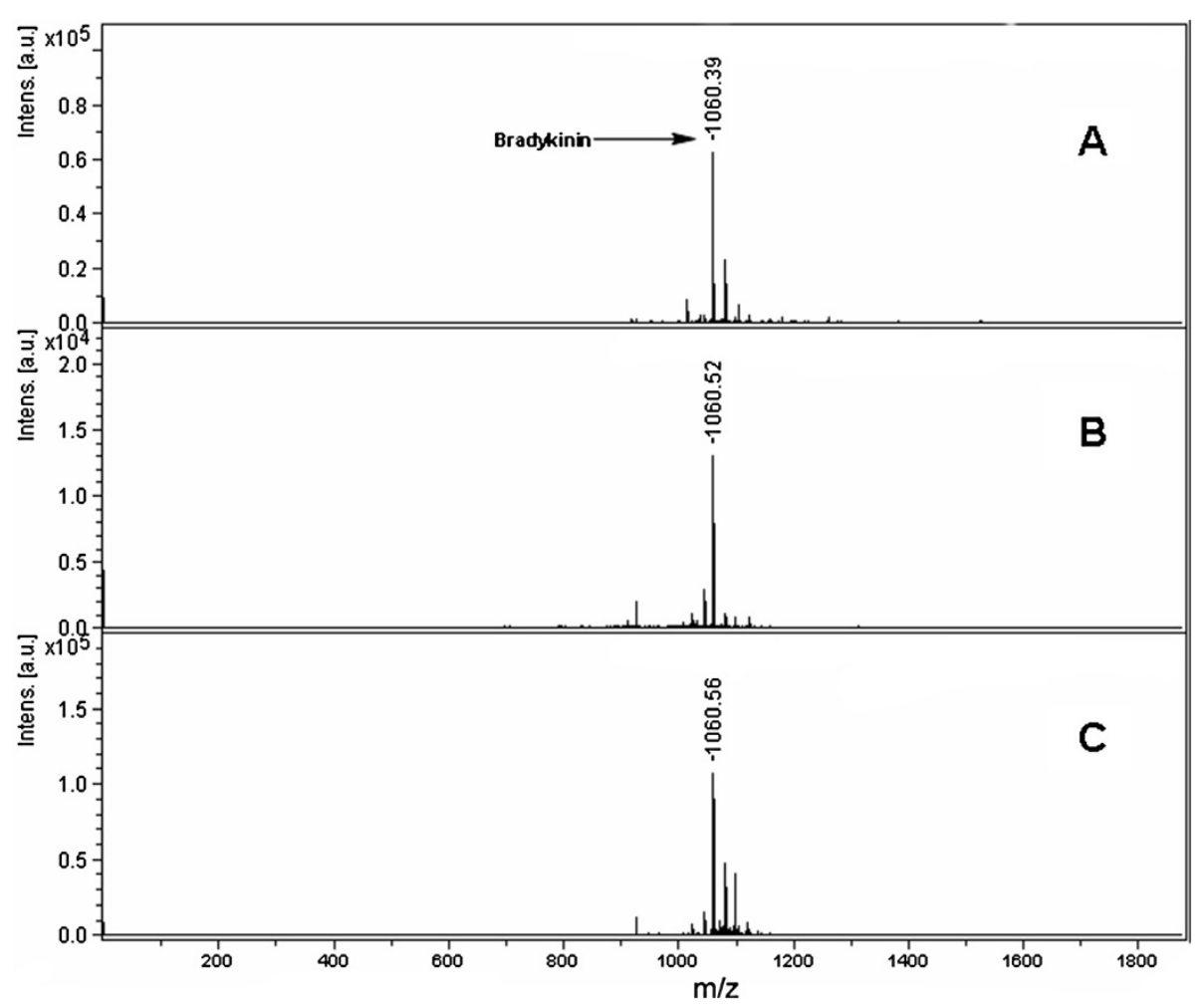

Figure 3 MALDI mass spectra of a peptide bradykinin (25 pM), recorded in reflector mode by averaging 600 laser shots with smart beam $(355 \mathrm{~nm}$ ) on MALDI-TOF-MS by applying different compounds as a matrix (A) 6 (B) 25 (C) 29. 
values (Table 2) also indicate this anomaly. For instance, compound 3 and 12 having the same $\lambda_{\max }$ i.e. $298 \mathrm{~nm}$, the signal intensity of 12 is one of the highest in both cases of bradykinin and renin substrate tetra-decapeptide, while, intensity levels of compound 3 are among the lowest.

\section{Method optimization}

Two important parameters, including are sample preparation method and solvent selection, which played an important role in getting a better signal to noise ratio $(\mathrm{S} / \mathrm{N})[30,31]$. One member of each class was used for optimization of the method before screening all the synthetic compounds. Sample preparation is one of the most important factors in MALDI-MS analysis. Three different commonly used sample preparation methods for laser desorption/ionization (LDI) were tried and compared by using different synthetic matrices, while $0.1 \%$
TFA: ACN was used as the suspending solvent. According to method A, the sample was mixed with synthetic matrix solution in a ratio of 1:2 and placed on a target plate. In method B, a thin layer of $1 \mu \mathrm{L}$ of synthetic matrix material solution was made on a target plate and then $0.5 \mu \mathrm{L}$ of analyte was added to it. Method $\mathrm{C}$ involves a similar strategy as that of method $\mathrm{B}$, except that the synthetic matrix solution was placed on top of the sample matrix layer (sandwich method). Analysis of bradykinin as an analyte under three different conditions showed that method A was the best sample spotting method and it was therefore selected for the study (Figure 1). The preference of method A was based on the high signal intensity and better $\mathrm{S} / \mathrm{N}$ ratio. Similarly, the solvent used for the solution/ suspension of newly evolved matrix materials is another important factor in sample preparation. Different solvent systems, such as acetone, methanol, acetonitrile, (1:1)

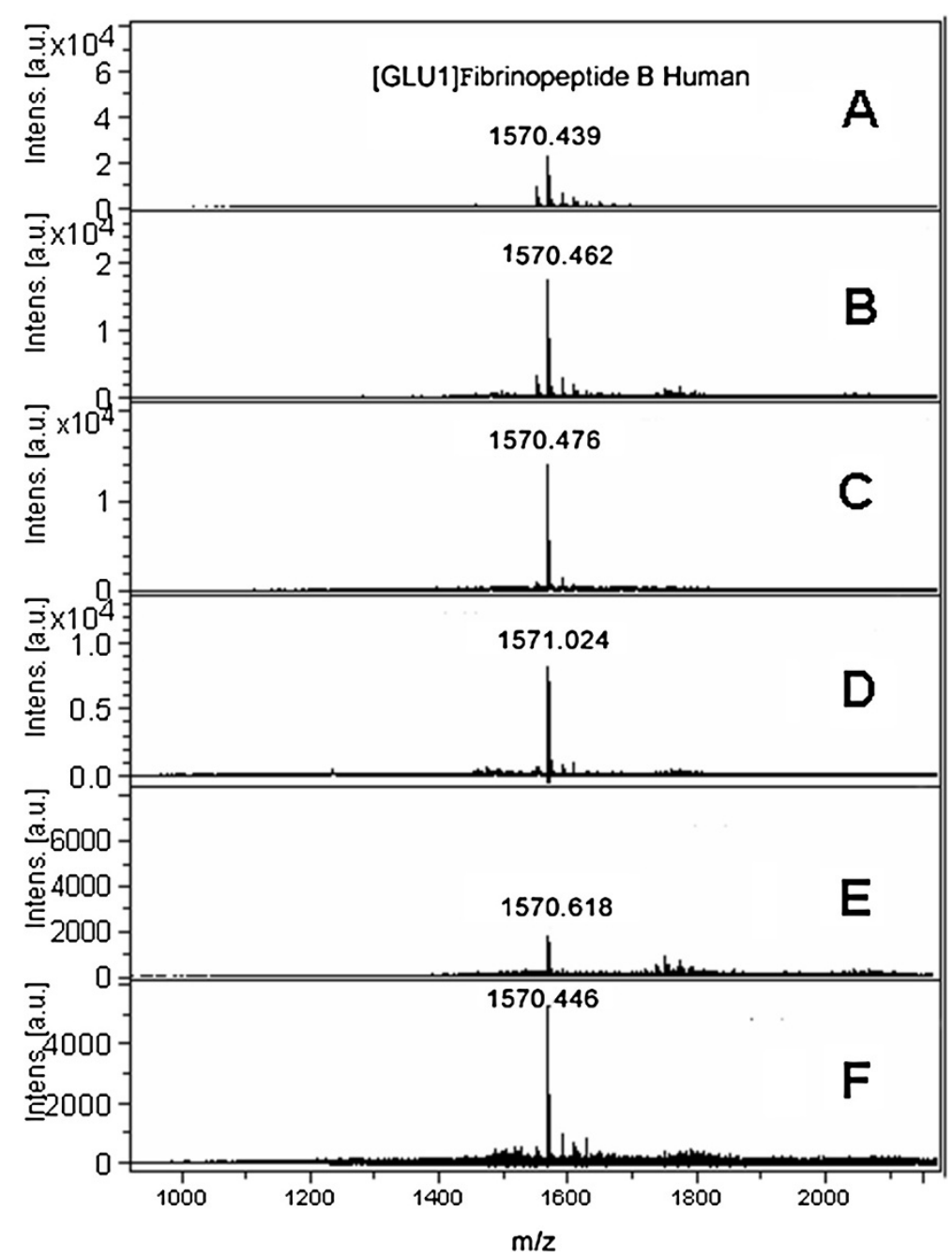

Figure 4 Sensitivity measurement mass spectra of compound 29 with different concentration of [Glu1]-fibrinopeptide B Human recorded in reflector mode by averaging 600 laser shots with smart beam (355 nm) on MALDI-TOF-MS (A) 1000 (B) 100 (C) 50 (D) 25 (E) 12.5 (F) $10 \mathrm{pM}$. 
water/methanol, (1:1) water/acetonitrile, and $0.1 \%$ TFA: ACN were used. $0.1 \%$ TFA: ACN was selected due to the better results of the above-mentioned mass spectral parameters (Figure 1).

\section{Screening of compounds}

All synthetic compounds were prepared for screening in $0.1 \%$ TFA: ACN with matrix to analyte volume ratio of 1:2 for the detection of low molecular weight peptides, bradykinin and renin substrate tetra-decapeptide $(<2000 \mathrm{Da})$.

Fourteen compounds of class I (benzimidazole derivatives) possessing $\lambda_{\max }$ around $213-325 \mathrm{~nm}$, were screened. All these new synthetic matrices of class I was comparable to existing MALDI matrix, HCCA in terms of intensity for the detection of peptides. However, the new matrices showed almost no background signals in the low mass range and hence were found to be suitable for the analysis of small peptides. Compounds 5, 8, 9, 11, 12 and 14 showed very high intensity $\left(>1 \times 10^{5}\right)$ for peptides (Table 2).

Twelve compounds of class II (coumarindione) were also screened as LDI matrix. All of them showed high intensity $\left(>1 \times 10^{4}\right)$ for low molecular weight peptides. Moreover, coumarin derivatives possess $\lambda_{\max }$ between 212-324 nm, most of the compounds showed best results.
However, coumarin dyes [32] and 3-hydroxycoumarin [33] have been reported as a MALDI matrix for the analysis of proteins and oligodeoxynucleotides, respectively. Five compounds of class III (flavones), possessing $\lambda_{\max }$ between 261-334 nm, were also tested as LDI matrices. Both peptides showed good signal intensity $\left(>1 \times 10^{4}\right)$ as presented in Table 2.

Benzimidazole derivatives (1-14) posses different aromatic substitution at $\mathrm{C}-2$. Aromatic ring substituted with electron withdrawing (halogen) and electron donating (-OH, -NR, -OR, R) groups at various positions. Compounds 6 and 14 which possess the same groups but at different orientations on phenyl ring i.e. meta and para, respectively, and it was found that para oriented $\mathrm{OH}$ groups exhibited better results. Moreover, in compound 12 , when hydrogen at $\mathrm{N}-1$ was substituted with phenyl ring as in compounds 5 then a decline in peptide signals were observed. In case of coumarins, compounds possessing furan ring (15 and 19) showed weak signals, whereas in dimethoxy substituted coumarin analogue (18) showed an enhanced signal in all coumarin derivatives. In flavone derivatives, dihydroxy containing flavone (29) showed high signal intensity as compare to compound 28 which lacks hydroxyl residues. Overall, signal intensities of analytes analyzed by newly developed matrices were promising. In all classes, different

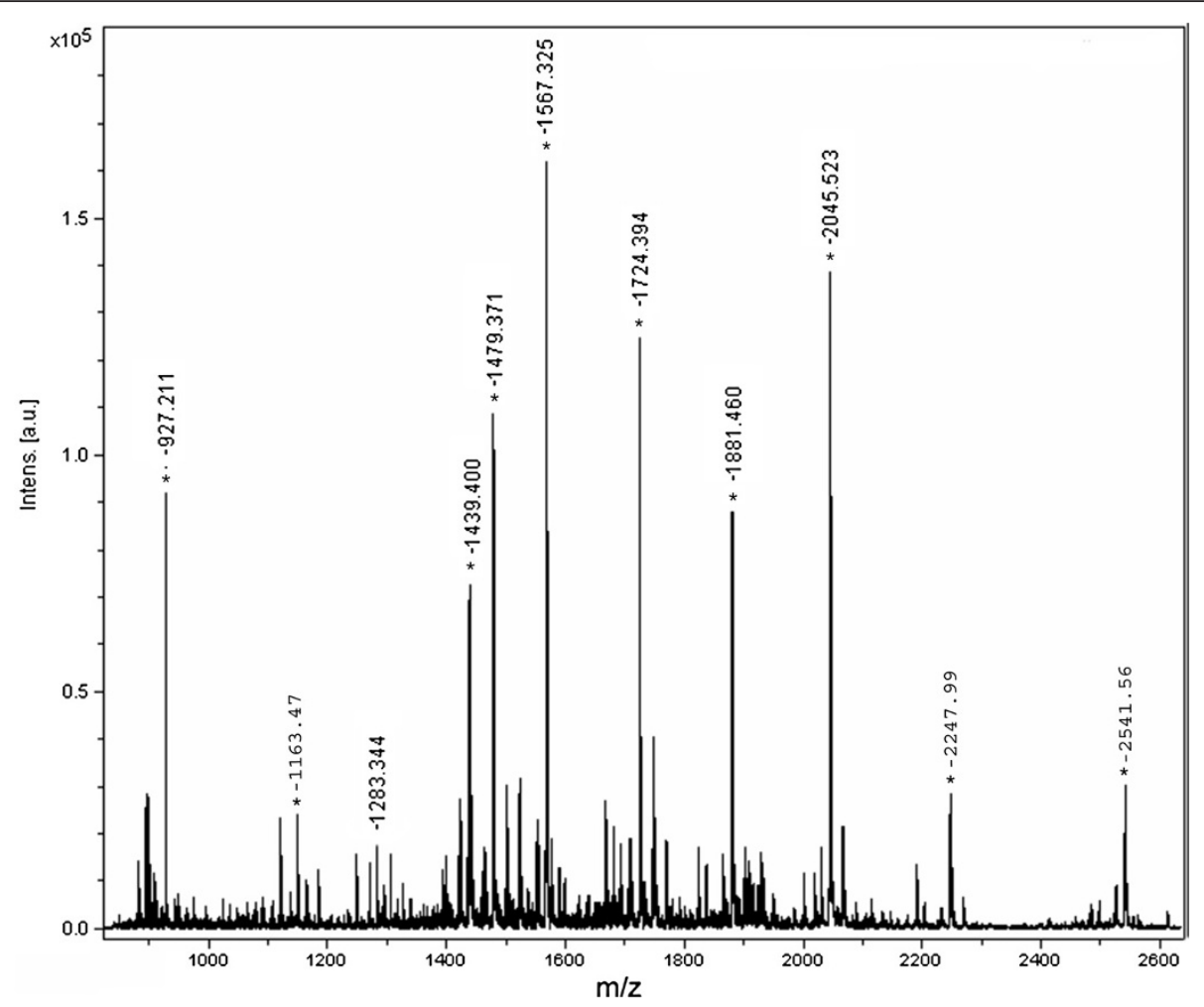

Figure 5 MALDI mass spectra of BSA-digest with compound 6 recorded in reflector mode by averaging 600 laser shots with smart beam $(355 \mathrm{~nm})$ on MALDI-TOF-MS. 
Table 3 Data-base search results of BSA-digest, analyzed with various matrices

\begin{tabular}{lccc}
\hline Compounds & $\begin{array}{c}\text { Average } \\
\text { Mascot Score }\end{array}$ & $\begin{array}{c}\text { Average number } \\
\text { of Peptides }\end{array}$ & $\begin{array}{c}\text { \% Sequence } \\
\text { coverage }\end{array}$ \\
\hline $\mathbf{6}$ & 68 & 27 & 53 \\
$\mathbf{2 5}$ & 101 & 17 & 28 \\
$\mathbf{2 9}$ & 41 & 16 & 29 \\
HCCA & 81 & 35 & 61 \\
\hline
\end{tabular}

substituents were attached which to act as an auxochrome through electron lone pair on hetro atom and conjugated double bond system. Both $n-\pi^{*}$ and $\pi-\pi^{*}$ transitions enhanced the hyperchromic effect and lead to a bathochromic shift thus resulted an increase in wavelength. This means, less energy is required for the excitation. This factor is directly related to the amount of laser power required to get a good intensity signal from a sweet spot on MALDI target. There were a large number of interfering signals observed in lower mass range with HCCA whereas the spectra recorded with the new matrices were very clean with nominal interfering signals (Figure 2). $0.1 \mathrm{mM}$ cholic acid solution was analyzed with three different matrices (compounds 6, 25 and 29) with a standard deviation of only \pm 0.033 , showing excellent reproducibility among all the matrices. The bradykinin peptide was analyzed with compounds 6,25 and 29 with a standard deviation of \pm 0.088 (Figure 3).

Selected numbers of each class of compounds were subjected to various screening. Sensitivity measurement of [Glu ${ }^{1}$-fibrinopeptide B was carried out by using compound 29 as an LDI matrix (Figure 4). Different concentrations of the analyte were screened including 1000,
$100,50,25,12.5$ and $10 \mathrm{pM}$ which showed intensity of $4 \times 10^{4}, 2 \times 10^{4}, 1.7 \times 10^{4}, 1.0 \times 10^{4}, 4.0 \times 10^{3}$ and $3.0 \times 10^{3}$, respectively. This unambiguously established the capability of new matrices to detect the less abundant analytes. Moreover, selected compounds from each class, including 6, 25 and 29, were also screened with BSAdigest sample which showed promising signals of peptides in the complex biological samples (Figure 5), assignment of significant peaks are mention in the Additional file 1: Table S1. The resulting mass spectrum was subjected to database search against Swiss-Prot, using MASCOT for the identification. The \% sequence coverage of BSA using compound 6 was 53 and found to be close with HCCA 61 (Table 3), proving that the newly synthetic matrices posses ability to analyze peptides in complex biological samples.

The homogeneity of newly synthetic matrices with the analyte solutions was also investigated. The achievement of the best spectral parameters (resolution, intensity and $\mathrm{S} / \mathrm{N}$ ratio) is attributed to the homogeneous mixing/embedding of analyte molecules into the matrix molecules. This homogeneity makes the finding of sweet spots easier and is particularly useful near the detection limit ranges. Moreover, In MALDI-MS analyses, the matrix should cocrystallize homogeneously with the analyte, and this phenomenon is helpful when recording of MALDI-MS spectra is carried out in an automatic mode. Figure 6 shows the stereomicroscopic (SM) surface images obtained using different synthetic matrices materials that deposit on the sample target plate. The images showed homogeneous mixing and crystal formation of various matrices with the analyte samples and thus finding of the sweet spot is efficient and offers better reproducibility of results.

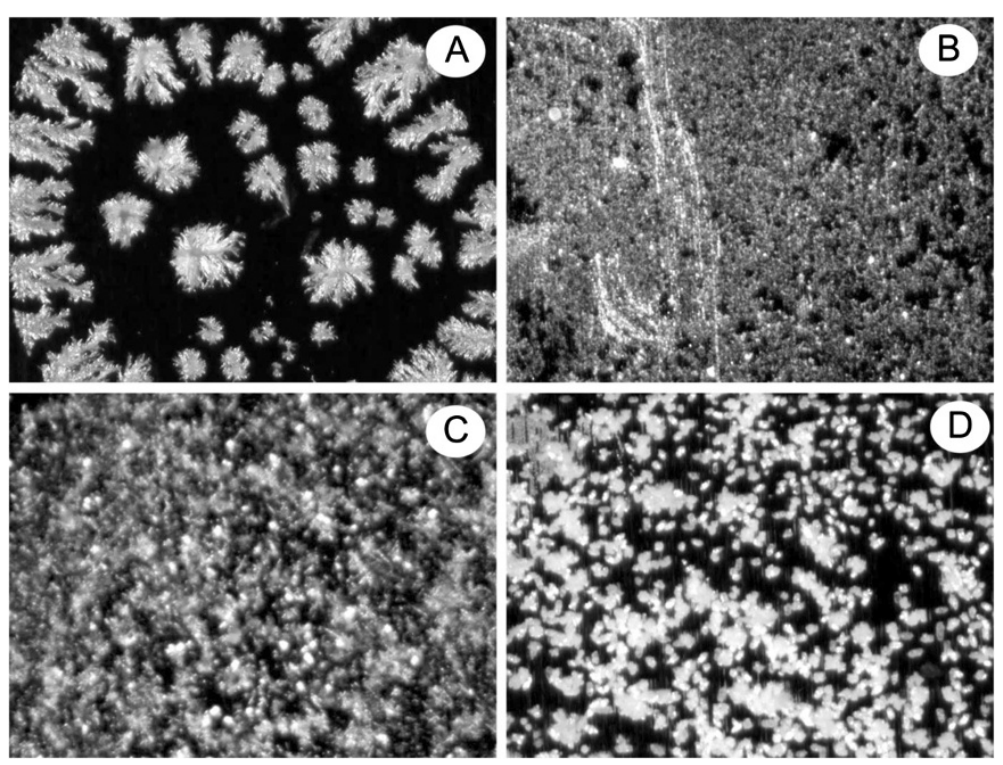

Figure 6 Microscopic image of cocrystallized analyte of bradykinin with various matrices (A) 6 (B) 25 (C) 29 (D) HCCA. 


\section{Conclusion}

Thirty one new matrices for laser desorption/ionization mass spectrometry (LDI-MS) have been studied and offered high performance and sensitivity which make them efficient platform for the analysis of small peptides. A number of conjugated aromatic systems in their structures ensure the laser energy transformations to the analytes. Furthermore, screening of a large number of organic compounds with various functionalities will be helpful for the development of structure-property relationship models, which in turn, could lead to a better understanding of the MALDI mechanism and discovery of better matrices in future.

\section{Additional file}

Additional file 1: Table S1. Peptide observed in tha MALDI TOF analysis of tryptic digestion of bovine serum albumin. Figure S1. The background spectra of matrices on off mode (A) compound 5 (B) compound $25(\mathbf{C})$ compound 27.

\section{Competing interests}

Authors declare that they have no competing interests.

\section{Authors' contributions}

SGM: Supervised the whole study and participated in method optimization. $A B$ : Participated in performing experimental and manuscript preparation. NS: involved in performing experimental and manuscript preparation. MN: Involved in the useful discussion. NA: Synthesized class-1 compounds. MK: Synthesized class-II and class-III compounds. KMK: Supervised synthetic work. MIC: Involved in the discussion and manuscript checking. AR: Participated in manuscript checking. All authors read and approved the final manuscript.

\section{Acknowledgements}

The authors are thankful to Prof. Dr. Nurul Kabir for providing his lab facility to record the microscopic images.

\section{Author details}

${ }^{1}$ Dr. Panjwani Center for Molecular Medicine and Drug Research, International Center for Chemical and Biological Sciences, University of Karachi, Karachi 75270, Pakistan. ${ }^{2}$ H.E.J. Research Institute of Chemistry, International Center for Chemical and Biological Sciences, University of Karachi, Karachi 75270, Pakistan. ${ }^{3}$ Department of Chemistry, Bahauddin Zakariya University (BZU), Multan 60800, Pakistan.

Received: 13 December 2012 Accepted: 17 April 2013

Published: 26 April 2013

\section{References}

1. Gross J, Strupat K: Matrix-assisted laser desorption/ionization mass spectrometry applied to biological macromolecules. Trends Analyt Chem 1998, 17:470-484

2. Dreisewerd K, Berkenkamp S, Leisner A, Rohlfing A, Menzel C: Fundamentals of matrix-assisted laser desorption/ionization mass spectrometry with pulsed infrared lasers. Int J Mass Spectrom 2003, 226:189-209.

3. Holle A, Haase A, Kayser M, Hohndorf J: Optimizing UV laser focus profiles for improved MALDI performance. J Mass Spectrom 2006, 41:705-716.

4. Dreisewerd K: The desorption process in MALDI. Chem Rev 2003, 103:395-425.

5. Meier MAR, Adams N, Schubert US: Statistical approach to understand MALDITOFMS matrices: Discovery and evaluation of new MALDI matrices. Anal Chem 2007, 79:863-869.

6. Wei J, Buriak JM, Siuzdak G: Desorption-ionization mass spectrometry on porous silicon. Nature 1999, 399:243-246.
7. Lee CS, Lee JH, Kang KK, Song HM, Kim H, Rhee HK, Kim BG: Laser desorption/ionization-mass spectrometry using mesoporous silicate as matrix for the analysis of various molecules. Biotechnol Bioprocess Eng 2007, 12:174-179.

8. Gorecka-Drzazga A, Bargiel S, Walczak R, Dziuban JA, Kraj A, Dylag T, Silberring J: Desorption/ionization mass spectrometry on porous silicon dioxide. Sensors and Actuators B 2004, 103:206-212.

9. Papac DI, Wong A, Jones AJS: Analysis of acidic oligosaccharides and glycopeptides by matrix-assisted laser desorption/ionization time-of-flight mass spectrometry. Ana Chem 1996, 68:3215-3223.

10. Metzger JO, Woisch R, Tuzynski W, Angermann R: New type of matrix for matrix-assisted laser desorption mass spectrometry of polysaccharides and proteins. Fresenius J Anal Chem 1994, 349:473-474.

11. Soltzberg $\sqcup$, Patel P: Small molecule matrix-assisted laser desorption/ionization time-of-flight mass spectrometry using a polymer matrix. Rapid Commun Mass Spectrom 2004, 18:1455-1458.

12. Dale MJ, Knochenmuss R, Zenobi R: Graphite/liquid mixed matrices for laser desorption/ionization mass spectrometry. Anal Chem 1996, 68:3321-3329.

13. Ren SF, Zhang L, Cheng ZH, Guo YL: Immobilized carbon nanotubes as matrix for MALDI-TOF-MS analysis: Applications to neutral small carbohydrates. J Am Soc Mass Spectrom 2005, 16:333-339.

14. Szabo Z, Vallant RM, Takasty A, Bakry R, Najam-ul-Haq M, Rainer M, Huck CW, Bonn GK: Laser desorption/ionization mass spectrometric analysis of small molecules using fullerene-derivatized silica as energy-absorbing material. J Mass Spectrom 2010, 45:545-552.

15. Najam-ul-Haq M, Rainer M, Huck CW, Hausberger $P$, Kraushaar $H$, Bonn GK: Nanostructured diamond-like carbon on digital versatile disc as a matrixfree target for laser desorption/ionization mass spectrometry. Anal Chem 2008, 80:7467-7472.

16. Kim HJ, Lee JK, Park SJ, Ro HW, Yoo DY, Yoon DY: Observation of low molecular weight poly(methylsilsesquioxane)s by graphite plate laser desorption/ionization time-of-flight mass spectrometry. Anal Chem 2000, 72:5673-5678

17. Piret G, Drobecq H, Coffinier Y, Melnyk O, Boukherroub R: Matrix-Free Laser Desorption/lonization Mass Spectrometry on Silicon Nanowire Arrays Prepared by Chemical Etching of Crystalline Silicon. Langmuir 2010, 26:1354-1361.

18. Gaëlle P, Doohun K, Hervé D, Yannick C, Oleg M, Patrik S, Rabah B: Surface-assisted laser desorption-ionization mass spectrometry on titanium dioxide $\left(\mathrm{TiO}_{2}\right)$ nanotube layers. Analyst 2012, 137:3058-3063.

19. Dupré $M$, Coffinier $Y$, Boukherroub R, Cantel S, Martinez J, Enjalbal C: Laser Desorption lonization Mass Spectrometry of protein digests on nanostructured silicon plates. J Proteom 2012, 75:1973-1990.

20. Coffinier $Y$, Szunerits S, Drobecq H, Melnyk O, Boukherroub R: Diamond nanowires for highly sensitive matrix-free mass spectrometry analysis of small molecules. Nanoscale 2012, 4:231-238.

21. Chen R, Chen S, Xiong C, Ding X, Wu CC, Chang HC, Xiong S, Nie Z: $\mathrm{N}$-(1-Naphthyl) Ethylenediamine Dinitrate: A New Matrix for Negative Ion MALDI-TOF MS Analysis of Small Molecules. J Am Soc Mass Spectrom 2012, 23:1454-1460.

22. He Q, Chen S, Wang J, Hou J, Wang J, Xiong S, Nie Z: 1-Naphthylhydrazine hydrochloride: A new matrix for the quantification of glucose and homogentisic acid in real samples by MALDI-TOF MS. Clin Chim Acta. in press.

23. Chen R, Xu W, Xiong C, Zhou X, Xiong S, Nie Z, Mao L, Chen Y, Chang HC: High-salt-tolerance matrix for facile detection of glucose in rat brain microdialysates by MALDI mass spectrometry. Anal Chem 2012, 84:465-469

24. Chen S, Chen L, Wang J, Hou J, He Q, Liu J, Wang J, Xiong S, Yang G, Nie Z: 2,3,4,5-Tetrakis(3',4'-dihydroxylphenyl)thiophene: A new matrix for the Selective analysis of low molecular weight amines and direct determination of creatinine in urine by MALDI-TOF MS. Anal Chem 2012, 84:10291-10297

25. Marijana P, Biljana P, Jasmina S, Zivadin DB, Jasmina DM, Tatjana M, Vesna V: Flavonoids as matrices for MALDI-TOF mass spectrometric analysis of transition metal complexes. Int J Mass Spectrom 2010, 290:39-46.

26. Khan KM, Khan M, Ambreen N, Rahim F, Naureen S, Perveen S, Choudhary MI, Voelter W: Synthesis and $\beta$-glucuronidase inhibitory potential of benzimidazole derivatives. Med Chem 2012, 8:421-427. 
27. Ambreen $\mathrm{N}$ : Synthesis of bioactive chromones and related heterocyclic compounds \& studies towards the synthesis of diethyl 2-(3-ox-3-(2-oxooxazolidin3-y/)-1- pheny/propylidene)malonates. HEJ Research Institute of Chemistry, International Center for Chemical and Biological Sciences, University of Karachi: PhD Thesis; 2009.

28. Horneffer V, Dreisewerd K, Ludemann HC, Hillenkamp F, Lage M, Strupat K: Is the incorporation of nalytes into matrix crystals prerequisite for matrix assisted laser desorption/ionization mass spectrometry? a study of five positional isomers of dihydroxybenzoic acid. Int J Mass Spectrom 1999, 185/186/187:859-870

29. Chinthaka SDM, Rodgers MT: Sodium cation affinities of commonly used MALDI matrices determined by guided ion beam tandem mass spectrometry. J Am Soc Mass Spectrom 2012, 23:676-689.

30. Nielen MWF: MALDI time-of-flight mass spectrometry of synthetic polymers. Mass Spectrom Rev 1999, 18:309-344.

31. Macha SF, Limbach PA, Savickas PJ: Application of nonpolar matrices for the analysis of low molecular weight nonpolar synthetic polymers by matrix-assisted laser desorption/ionization time-of-flight mass spectrometry. J Am. Soc Mass Spectrom 2000, 11:731-737.

32. Perera IK, Kantartzoglou S, Dyer PE: Coumarin laser dyes as matrices for matrix assisted UV laser desorption/ionization mass spectrometry. Int. J. Mass Spectrom Ion Processes 1994, 137:151-171.

33. Zhang Z, Zhou L, Zhao S, Deng H, Deng Q: 3-hydroxycoumarin as a new matrix for matrix-assisted laser desorption/ionization time-of-flight mass spectrometry of DNA. J Am Soc Mass Spectrom 2006, 17:1665-1668.

Cite this article as: Musharraf et al.: Benzimidazole, coumrindione and flavone derivatives as alternate UV laser desorption ionization (LDI) matrices for peptides analysis. Chemistry Central Journal 2013 7:77.

\section{Publish with ChemistryCentral and every scientist can read your work free of charge \\ "Open access provides opportunities to our colleagues in other parts of the globe, by allowing anyone to view the content free of charge." \\ W. Jeffery Hurst, The Hershey Company. \\ - available free of charge to the entire scientific community \\ - peer reviewed and published immediately upon acceptance \\ - cited in PubMed and archived on PubMed Central \\ - yours - you keep the copyright \\ Submit your manuscript here: \\ http://www.chemistrycentral.com/manuscript/<smiles>c1ccccc1</smiles> \\ Chemistry Central}

